\title{
An Educational Experiment Obviously Hidden In-Between
}

DAG BOUTSEN - CARL BOURGEOIS

Faculty of Architecture KU Leuven 
For one and a half year, we have been renting the 24th floor of the abandoned WTC1-building, a tower waiting for total restructuring financed by a Regulated Real-estate Investment Trust (BE-REIT), listed on Euronext Brussels. $1500 \mathrm{~m}^{2}$ of free space.

This floor is located next to the north station, which connects people between the big city and smaller ones. The North Station connects trains with trams and buses. The North Station connects fast food with a bike point. The North Station is, or was a building. Not anymore. Today, it does not imply connection, only separation, brutal transition, inhospitability, emptiness, refreshed decay.

The North Station is lost between neighborhoods so different from each other that you can no longer speak of a city. The Royal Axis between a palace in a park and a palace on a park, the low part of the Rogierstraat with mattresses on the steep sidewalk-window, the slowly westernized 'Oriental' Brabantstraat, the criminal Aarschotstraat, and then on the other side the 'Noord'(wijk)quarter. Wijk is the Dutch word for neighbourhood. Neighborhood? Distant-hood! On which side is Brussels actually? Where do I go?

The difference between the west side of the station and the east side is the wind. And the water. The wind cannot turn any direction into a 19th-century urban fabric. And isn't the Zenne somewhere there? Or is there only the channel?

During this period, there was that constellation of hip activities that have 'occupied' the tower with all sorts of temporary use, creating a sort of buzz or hype: Jubilee and other artists on floor 25, the architectural office 51 N4E on the 16th floor, then AWB (Architecture Workroom Brussels) that also brought a Rotterdam architecture biennial to Brussels with 'You are here', an exciting exhibition about the urbanism of the transition. As such, we were able to seamlessly plug in with our ethics lessons.

There are a number of things that came together on that floor. First of all, there is that exciting experience of an open floor in a dilapidated, 'skyscraper', as a remnant of a utopian capitalist 'robbery project': the Manhattan project as 'urbicide' of one of Brussels' most lively, popular neighborhoods, the Noordwijk, with the Antwerpse Steenweg as the central axis of popular entertainment. The office district is becoming empty and is in urgent need of a radical renewal by breaking through the monofunctional. In addition, at the back side of the tower, there is the Maximilian Park where the asylum seekers must apply for asylum, which brought the harrowing problem to our back door. That was a rich and at the same time always debatable context, which directly or indirectly determined the conversation in almost every discussion. 
The physical aspect of the location was certainly an important factor: that gigantic playing field with that eternally spectacular view of Brussels from above, a space without divisions where you had to conquer your place as a class nomadic, it was always a special experience.

Cozy squares, green water, lively neighborhoods, pleasant shops, visible productivity, local industry, mixed population, learning environments, soft mobility, smart reuse, pleasant stay, circular economy and slow food. All of these have been worked on, there on the 24th floor on top of the WTC1 tower. That is what they have been dreaming of for one and a half years. And still are.

On a high island without wind. Secluded and not at all. With a look at desolation, and at the same time towards another future. The strength of that temporary and nomadic school came from the absurd interweaving of all those worlds that come together somewhere in height. This power even occasionally resulted in a brutal critique of 'established' values and stakeholders.

We have always been convinced that a good pedagogy comes down to a good conversation between peers, and you need at most a few seats for that. In the case of an architectural education, you could argue for a table to put an artifact on top that is subject of conversation. Everything else is luxurious.

And there may be luxury, but one should at least be aware of it. Moving into a fully non-equipped floor and thus temporary reducing all comfort or luxury therefore seemed to justify our decision, maintaining that thought that this would intensify the conversations and the effective pedagogy.

The experiment teaches numerous lessons, of which a publication will testify. In addition, the experience lives in the generation of students and teachers who were allowed to experience it, with all its shortcomings and all its highlights, but at least with the realization that we have not avoided the challenge.

Learning is experimenting, is seeking to find the solution rather than finding it.

\section{REFERENCE}

New publication: 'WTC24: The school of temporal permanence', on '(De-)Schooling at WTC: Reports from the 24th Floor' and 'One and a half years at WTC: Architecture, Education, Practice 


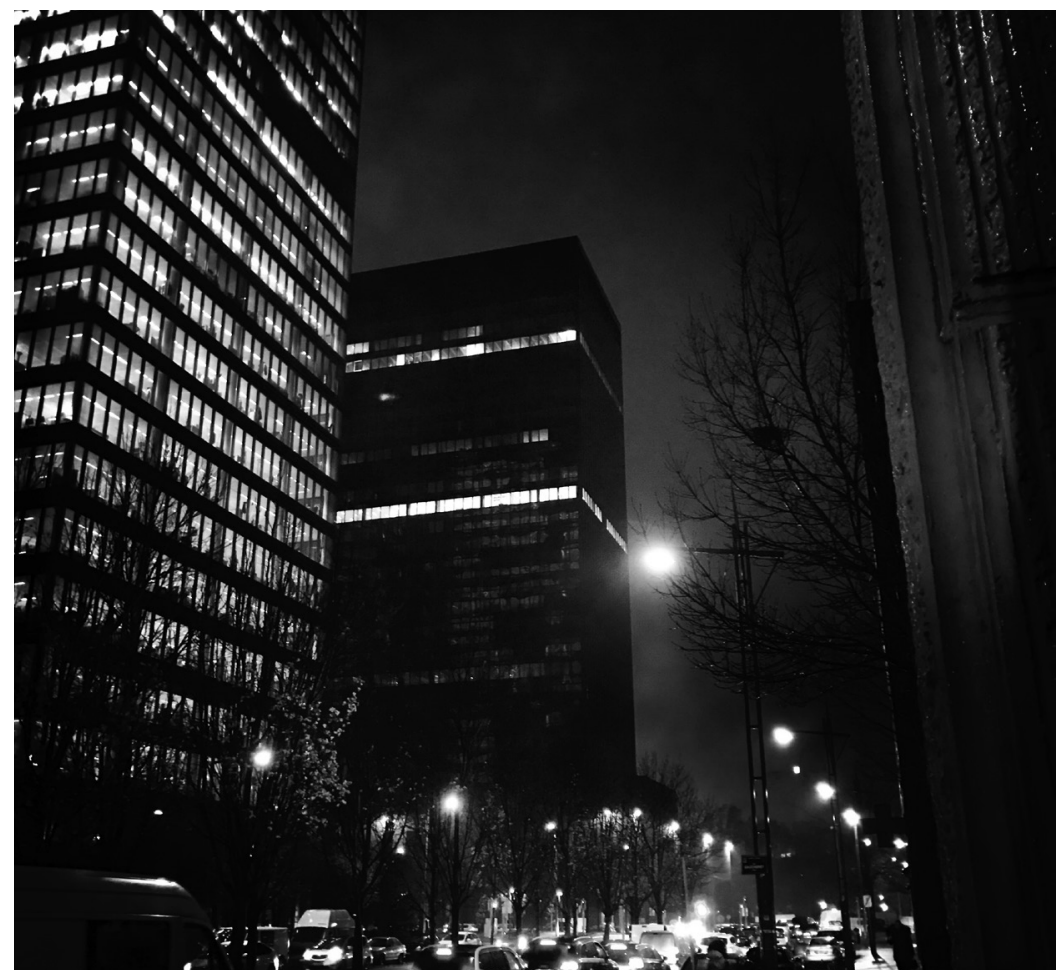

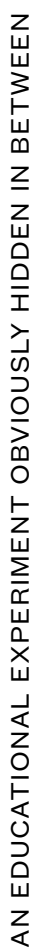

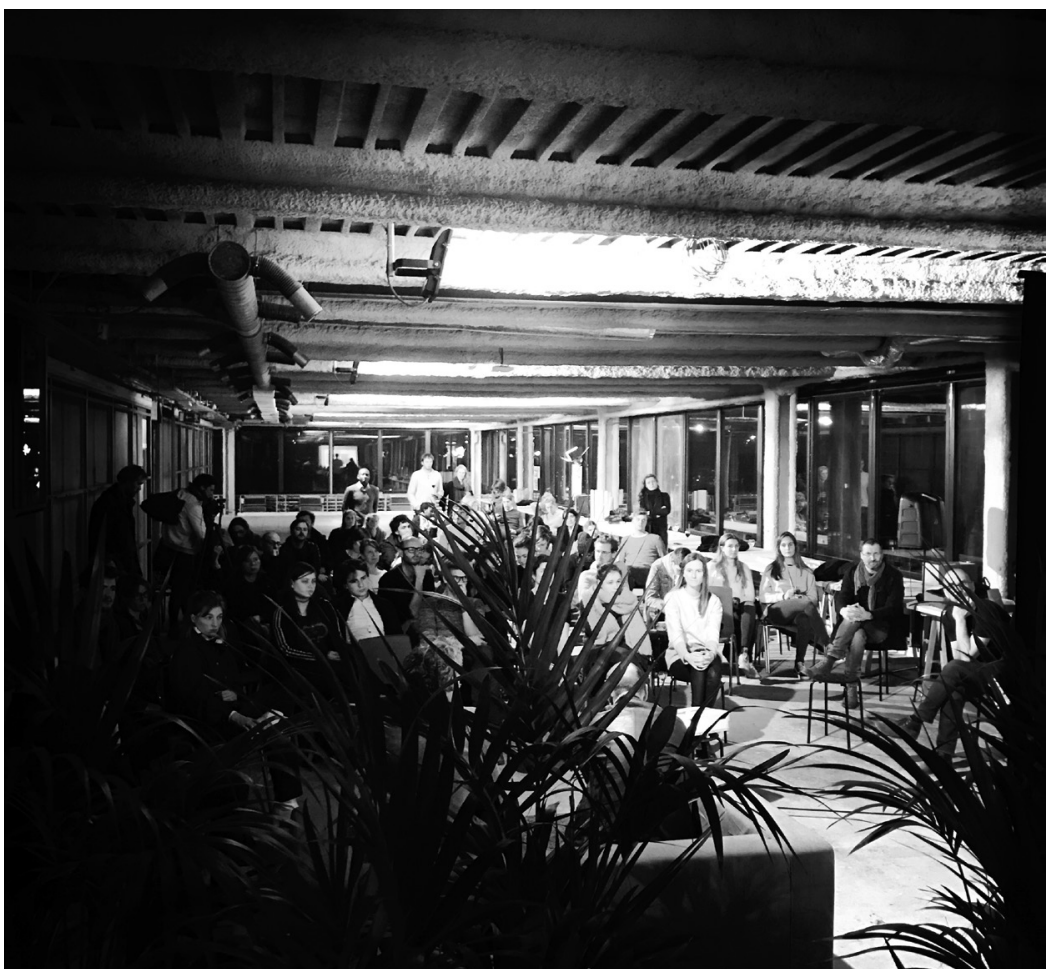




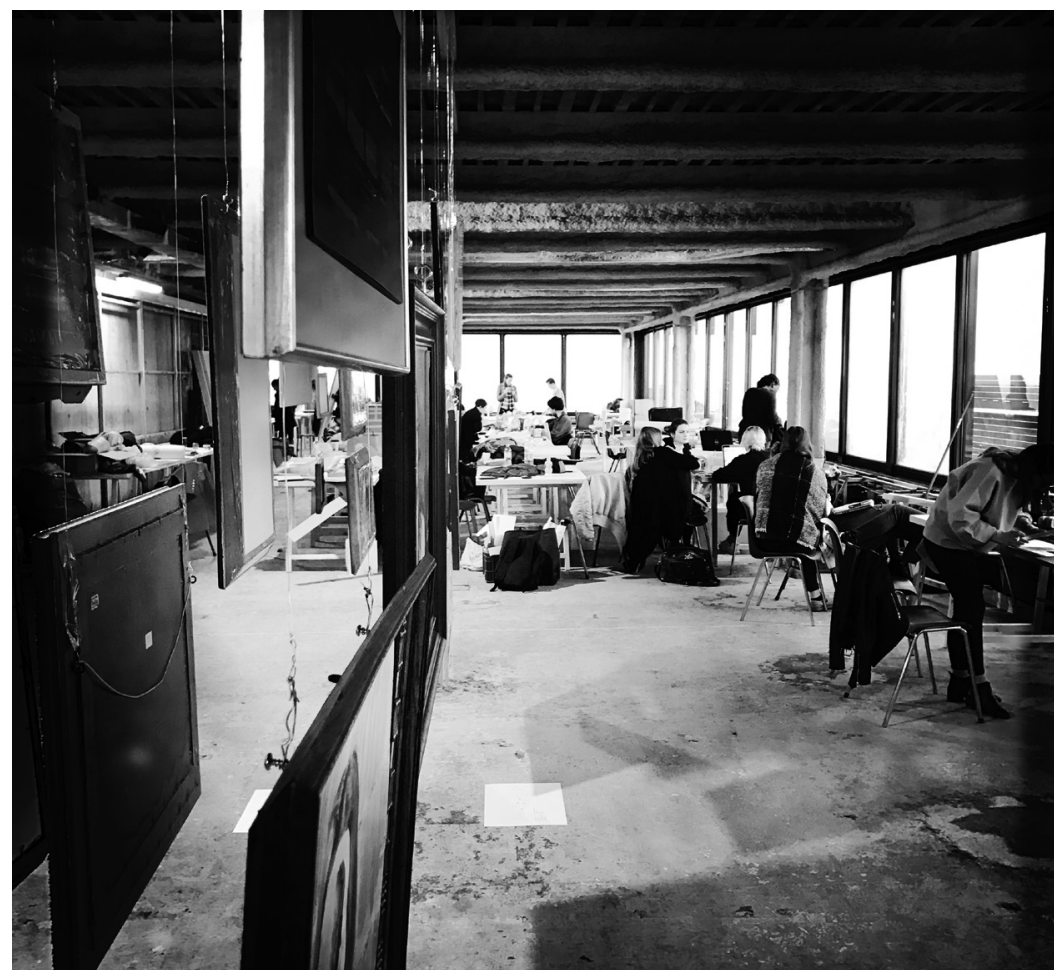

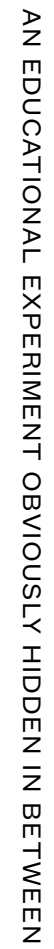

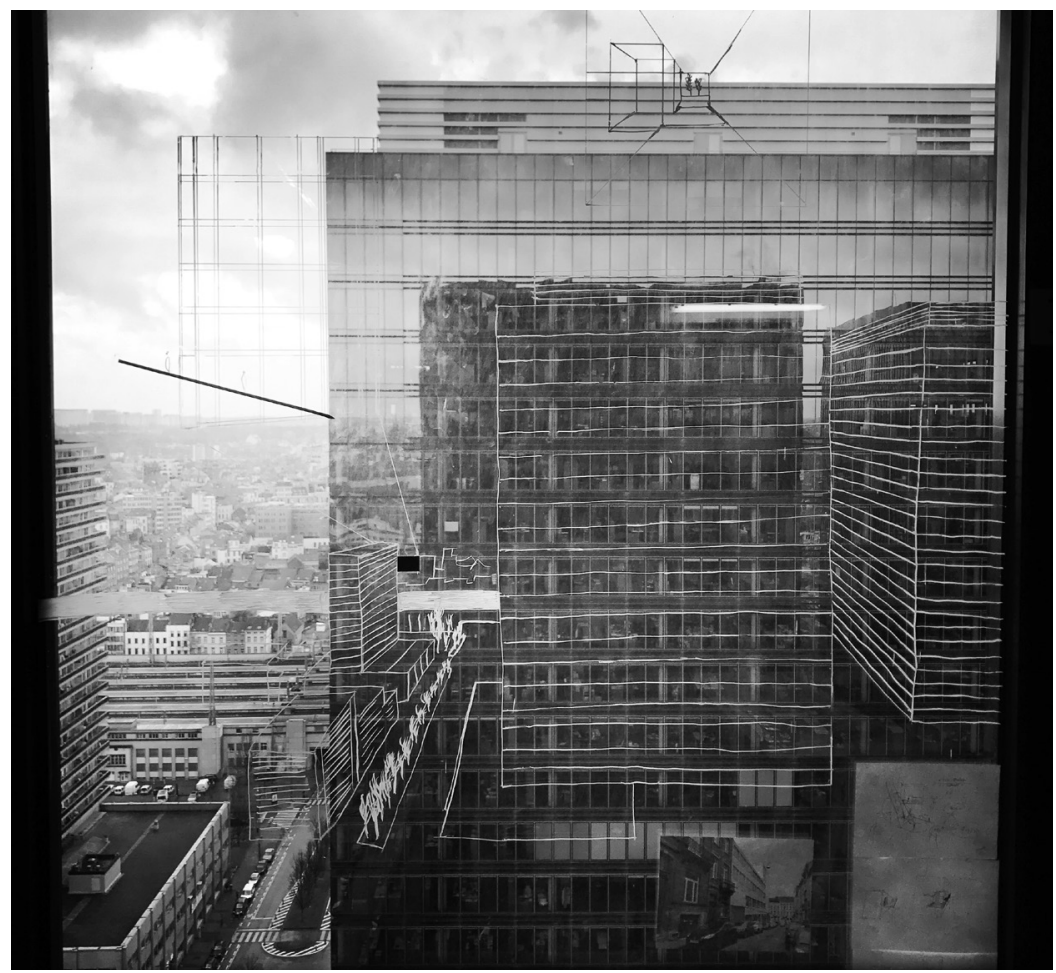

$\stackrel{1}{0}$

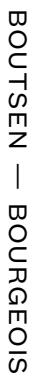




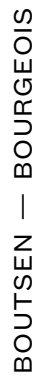

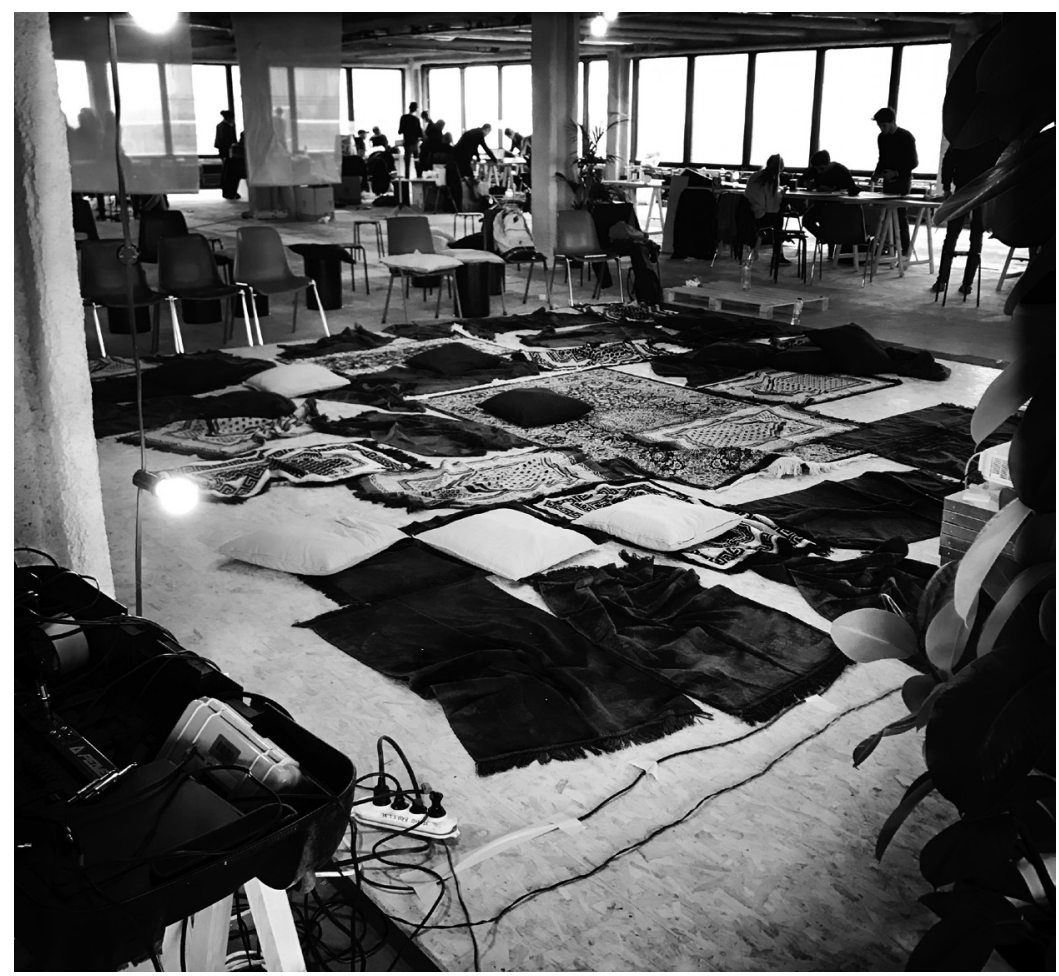

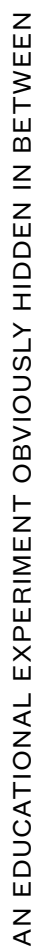

